\title{
DESIGN, FINITE ELEMENT ANALYSIS, AND EXPERIMENTAL PERFORMANCE EVALUATION OF A THERMALLY-ACTUATED BEAM USED TO ACHIEVE LARGE IN-PLANE MECHANICAL DEFLECTIONS
}

\author{
Peter B. Allen, Jeffery T. Howard, Edward S. Kolesar and Josh M. Wilken
}

Texas Christian University, Department of Engineering, TCU Box 298640, Fort Worth, TX 76129

\begin{abstract}
Numerous electrically-driven microactuators have been investigated for positioning individual elements in microelectromechanical systems (MEMS). The most common modes of actuation are electrostatic, magnetostatic, piezoelectric and thermal expansion [1]. Unfortunately, the forces produced by electrostatic and magnetostatic actuators tend to be small, and to achieve large displacements, it is necessary to either apply a large voltage or operate the devices in a resonant mode. On the other hand, piezoelectric and thermal expansion actuators can be configured to produce large forces and large displacements. Unfortunately, piezoelectric materials are not routinely supported in the fabrication processes offered by commercial MEMS foundries. Consequently, these limitations have focused attention on thermally-actuated devices for generating the large forces and displacements frequently required to position and assemble complex MEMS [2].
\end{abstract}

\section{INTRODUCTION}

This research focuses on the design, finite element analysis and experimental performance evaluation of a MEMS thermally-actuated beam $[3,4]$. The motivation is to present a unified description of the behavior of the thermal beam so that it can be adapted to a variety of applications in the microsensor and microactuator arenas. As depicted in Figure 1, a MEMS polysilicon thermally-actuated beam uses resistive (Joule) heating to generate thermal expansion and movement. When current is passed through the actuator from anchor-to-anchor, the larger current density in the "hot" arm causes it to heat and expand more than the "cold" arm. Since both arms are joined at their free (released) ends, the actuator tip is forced to move in an arc-like pattern. Removing the current from the device allows it to return to its equilibrium state. To be a useful MEMS device, a thermallyactuated beam will need to produce incremental in-plane mechanical beam tip deflections that span $0-10 \mu \mathrm{m}$ while generating force magnitudes greater than $10 \mu \mathrm{N}$.

\section{EXPERIMENTAL}

The thermally-actuated beam design (Figure 1) was accomplished with the L-Edit ${ }^{\circledR}$ software program, and they were fabricated using the Multi-User Microelectromechanical Systems (MEMS) Process ${ }^{\circledR}$ (MUMPs) foundry at the Microelectronics Center of North Carolina (MCNC) [5].

The finite element analysis was accomplished with the IntelliCAD ${ }^{\oplus}$ computer program. As depicted in Figure 2, this CAD software incorporates an MCNC fabrication process description file that verifies and generates a 3-D solid model of a given MEMS design. As illustrated in Figures 3 and 4, the thermal and electromechanical finite element analyses yielded beam tip deflections and forces consistent with experimental observations. When the "hot" arm's temperature is $600^{\circ} \mathrm{C}$ (Joule heating), the resulting beam tip deflection is $4.55 \mu \mathrm{m}$. For a beam tip force of $14 \mu \mathrm{N}$, the displacement was calculated to be $12.9 \mu \mathrm{m}$. The resonant frequency, without damping, was calculated to be $74.7 \mathrm{kHz}$.

The MEMS thermally-actuated beam performance was also experimentally characterized. As depicted in Figure 5, when the drive voltage was varied between 0 and 8 VDC, tip deflections spanning $0-8 \mu \mathrm{m}$ were observed. The corresponding tip forces spanned $0-12 \mu \mathrm{N}$. The resonant frequency in ambient air was $68.7 \mathrm{kHz}$. A measure of the reliability of the thermal beam was established to be greater than 2 million cycles, when continuously operated with a 60 $\mathrm{Hz}$, 4-volt amplitude square wave.

\section{REFERENCES}

[1] L. Ristic (ed.), Sensor Technology and Devices, Artech House, Norwood, MA, 1994.

[2] C.S. Pan and W. Hsu, "An electro-thermally and laterally driven polysilicon microactuator," I. Micromech. Microeng., Vol. 7, pp. 7-13, 1997.

[3] H. Guckel, et al., "Thermo-magnetic metal flexure actuators," Solid-State Sen. Act. Workshop, Hilton Head Island, SC, June 22-25, 1992, pp. 73-5.

[4] J.H. Comtois and V.M. Bright, "Surface micromachined polysilicon thermal actuator arrays and applications," SolidState Sen. Act. Workshop, Hilton Head Island, SC, June 2-6, 1996, pp. 174-6.

[5] P.B. Allen, J.M. Wilken and E.S. Kolesar, "Design, Fabrication and Performance Evaluation of Several Electrical and Mechanical Silicon Microstructures Realized using the Emerging Technology of Microelectromechanical Systems (MEMS)," Proc. 1997 Conf. ASEE, Houston, TX, March 2325, 1997, pp. 43-8.

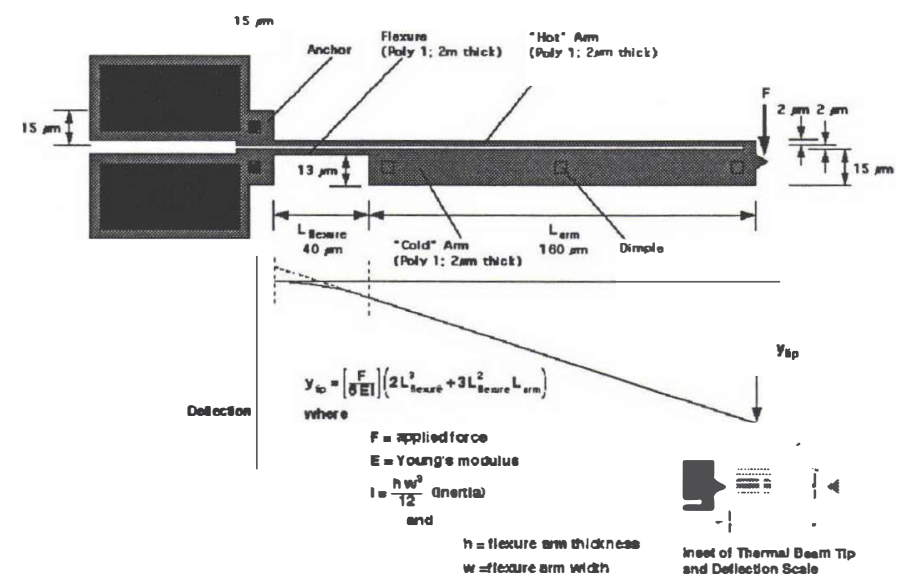

Figure 1. Polysilicon thermal beam design and analytical relationship relating tip deflection and tip force. The $2.0 \mu \mathrm{m}$ thick polysilicon thermally-deflectable beam is suspended above a silicon nitride dielectric layer via the sacrificial glass etch process. The three dimples (square-shaped features) positioned along the length of the wide segment of the beam act as near-frictionless bearings. The inset depicts a 
magnified view of the thermal beam's tip ("pointer" feature) and scale used to measure deflection.

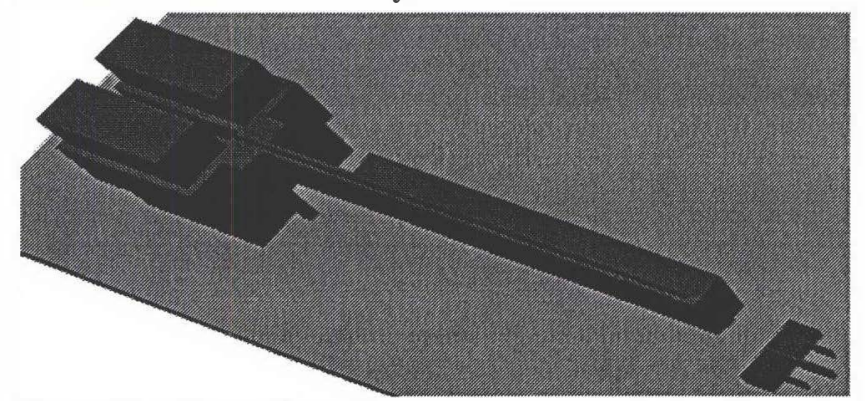

Figure 2. Three-dimensional solid model of the thermal beam generated by the IntelliCAD program.

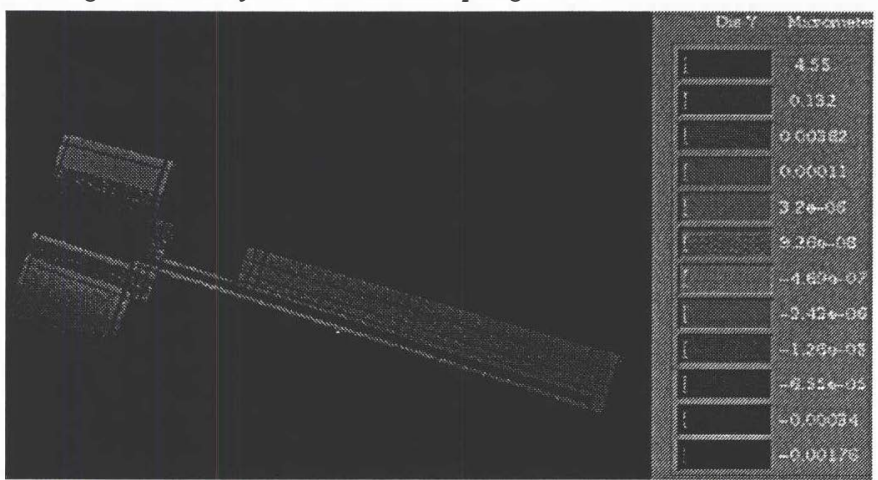

Figure 3. Thermomechanical performance of the thermal beam. With a 6 VDC drive signal, the characteristic temperature of the narrow thermal beam was $600^{\circ} \mathrm{C}$. The average tip temperature of the wide arm was $150^{\circ} \mathrm{C}$. The resulting inplane deflection of the beam's tip is $4.55 \mu \mathrm{m}$.

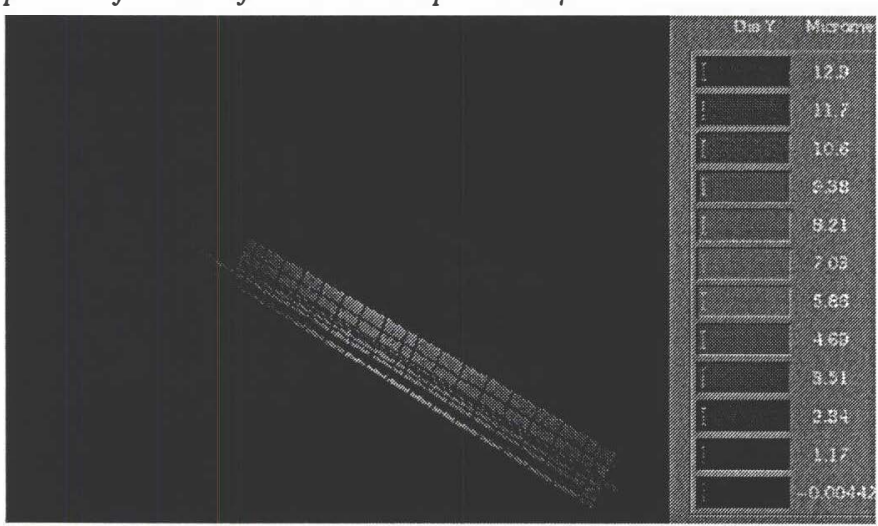

(a)

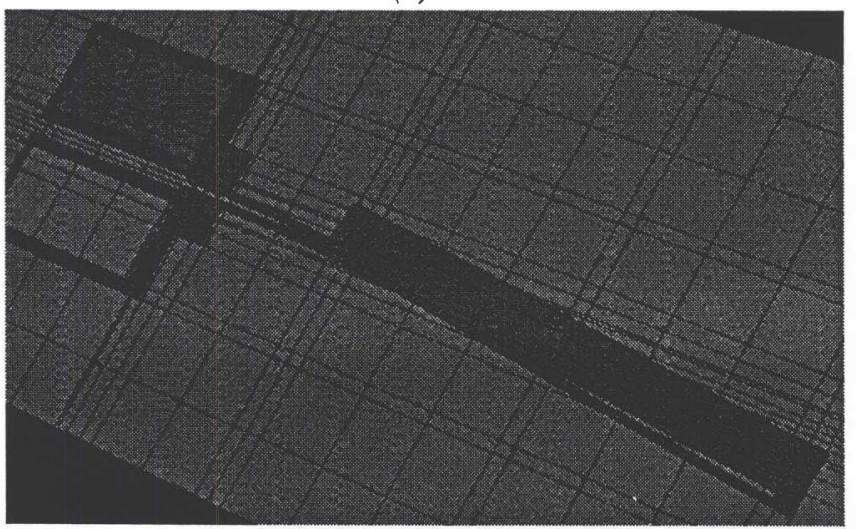

(b)

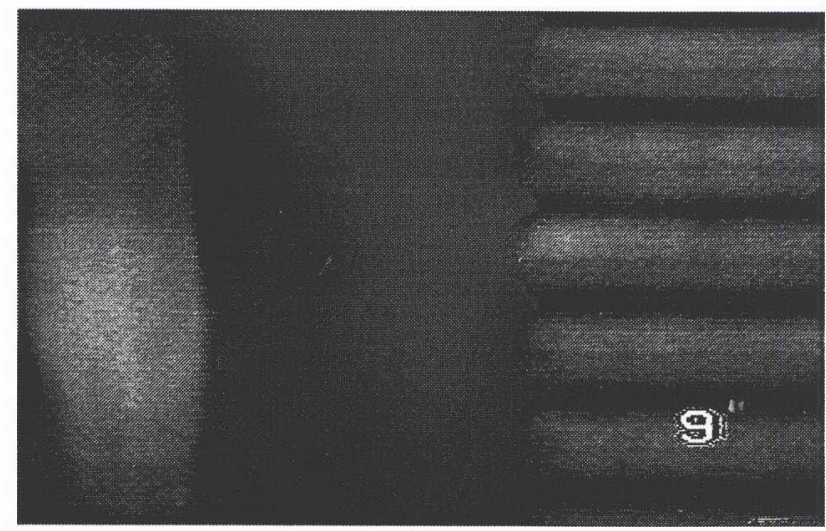

(c)

Figure 4. Electromechanical performance of the thermal beam. (a) Upon the application of a $14 \mu \mathrm{N}$ force to the tip of the beam (Figure 1), the resulting in-plane tip deflection was predicted to be $12.9 \mu \mathrm{m}$ (the analytical model in Figure 1 predicts a deflection of nearly $10 \mu \mathrm{m}$.. (b) The resonant frequency of the thermal beam was calculated to be $74.7 \mathrm{kHz}$ (note that the beam now deflects about its equilibrium inplane position). (c) The experimentally obsened resonant frequency was $68.7 \mathrm{kHz}$.

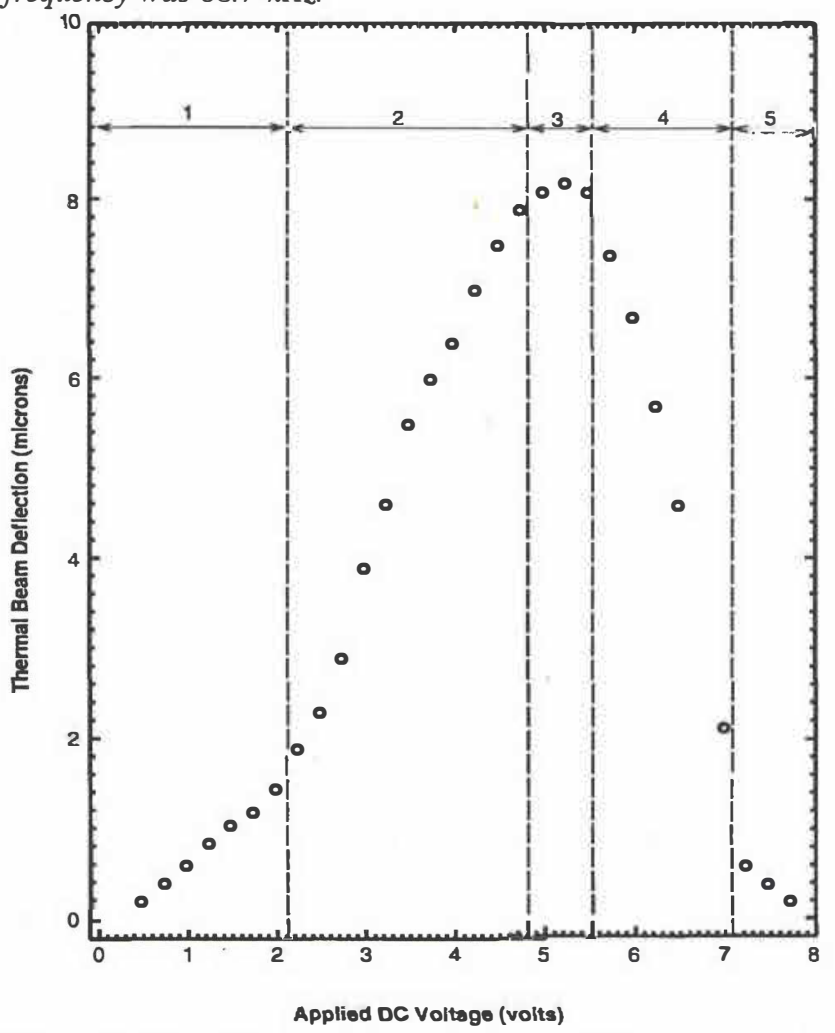

Figure 5. Plot of the thermal beam's applied direct current $(D C)$ voltage versus tip deflection experimental data segmented into 5 behavioral regions. (Each data symbol represents the arithmetic average of three values). Key: Region 1: Elastic mode (buckling of the narrow width beam element not observed). Region 2: Elastic and reversible buckling mode. Region 3: Transition from the elastic to plastic mode (irreversible buckling). Region 4: Plastic mode (pronounced buckling; return to the zero-deflection position no longer occurs). Region 5: Transition to thermal beam failure. 